\title{
Physically based constitutive description of OFHC copper at hot working conditions
}

\author{
H. Mirzadeh* \\ School of Metallurgy and Materials Engineering, College of Engineering, University of Tehran, \\ P.O. Box 11155-4563, Tehran, Iran
}

Received 22 June 2014, received in revised form 15 July 2014, accepted 17 July 2014

\begin{abstract}
The hot deformation behavior of oxygen-free high-conductivity (OFHC) copper was studied through constitutive analysis by two distinct approaches, which consider the material parameters as apparent and physically based ones. The latter approach accounts for the dependence of the Young's modulus and the self-diffusion coefficient on temperature, which can simply result in a reliable constitutive equation. It was shown that the theoretical exponent of 5 and the lattice self-diffusion activation energy of $\mathrm{Cu}\left(197 \mathrm{~kJ} \mathrm{~mol}^{-1}\right)$, corresponding to the glide and climb of dislocations as the controlling deformation mechanism, can be set in the hyperbolic sine law to describe the peak flow stresses. It has been also demonstrated that these two approaches are consistent with each other and the simple physically-based approach described in this work can be considered as an alternative one for the conventional apparent approach.
\end{abstract}

K e y w or d s: thermomechanical processing, compression test, Zener-Hollomon parameter

\section{Introduction}

Commercial wrought copper in bars, wire, sheets, and rods is marketed as electrolytic tough pitch, oxygen-free copper, phosphorized copper, and arsenical copper [1]. Copper with an oxygen content of less than about $40 \mathrm{ppm}$ is generally designated oxygenfree high-conductivity (OFHC) copper and is extensively used in electronic component and printed circuit board manufacture [2]. Since copper has a medium to low stacking fault energy of about $40 \mathrm{~mJ} \mathrm{~m}^{-2}$, dynamic recrystallization (DRX) normally occurs during its hot working $[2,3]$. At relatively low temperatures and high strain rates, the flow stress passes through a single peak before decreasing to the steady state level. Conversely, at relatively high temperatures and low strain rates, oscillations in flow stress are usually observed, which die out as steady state flow conditions are attained $[2,4]$. These observations are in accordance with the general trend of DRX flow curves in hot working [5-10].

The understanding of the material constitutive response to the imposed conditions and the characteriz- ation of hot working behavior are two of the prerequisites for the implementation of shaping technology in the industry, which requires multistage processing sequences to obtain desired final microstructure [11-14]. The modeling of hot flow stress and the prediction of flow curves are important in metal forming processes such as rolling and forging from the mechanical and metallurgical standpoints because any feasible mathematical simulation needs accurate flow description [15-24].

A common constitutive equation in hot working for a wide range of temperatures and strain rates is expressed by a hyperbolic sine relation of the form $Z=\dot{\varepsilon} \exp (Q / R T)=A[\sinh (\alpha \sigma)]^{n}$, where $Z$ is the Zener-Hollomon parameter, $Q$ is the deformation activation energy, $\dot{\varepsilon}$ is the strain rate, $T$ is the absolute temperature, and finally $A$ (the hyperbolic sine constant), $n$ (the hyperbolic sine power), $\alpha$ (the stress multiplier) are the material parameters [25-30]. Conventionally, $n$ and $Q$ are considered to be apparent parameters in the hyperbolic sine law, because no account is generally taken of the internal microstructural state and they are only derived from plots generated

*Corresponding author: tel.: +982182084127; fax: +982188006076; e-mail address: hmirzadeh@ut.ac.ir 
Table 1. The details of the hot compression experiments on OFHC copper

\begin{tabular}{cccc}
\hline Temperature $(\mathrm{K})$ & Strain rate $\left(\mathrm{s}^{-1}\right)$ & Initial grain size $(\mu \mathrm{m})$ & Reference \\
\hline $725-1075$ & $0.002-0.2$ & $10-800$ & {$[4]$} \\
$773-1173$ & $0.005-20$ & 500 & {$[32]$} \\
$573-1223$ & $0.001-100$ & - & {$[33]$} \\
$473-1073$ & $0.01-10$ & 70 & {$[34]$} \\
$298-814$ & $0.0004-6000$ & 62 & {$[35]$} \\
\hline
\end{tabular}

by experimental data and the assumption that the microstructure remains constant. However, the consideration of physically based values will result in a more reliable constitutive equation [31].

In the current work, the constitutive behavior of OFHC copper during hot deformation will be studied by both consideration of apparent parameters and physically based material parameters and finally a reliable constitutive equation will be proposed for hot deformation of this material.

\section{Experimental materials and procedures}

The flow stress data of OFHC copper, hot compressed at deformation temperatures between 450 and $900{ }^{\circ} \mathrm{C}$ under strain rates of 0.0004 to $100 \mathrm{~s}^{-1}$, were taken from the literature $[4,32-35]$. Note that the description of flow stress by the hyperbolic sine equation is incomplete, because no strain for determination of flow stress is specified. Therefore, characteristic stresses that represent the same deformation or softening mechanism for all flow curves, such as steady state or peak stress, should be used in this equation. Since the peak stress $\left(\sigma_{\mathrm{P}}\right)$ is the most widely accepted one in order to find the material constants during hot working $[12,36,37]$, the values of peak stress were taken with emphasis on the consistency of stress level among different research works.

Since the flow data has been taken from the literature and the details of the considered materials and experiments in each research work are different (Table 1), some other factors such as grain size, texture, and small variations in chemical compositions can affect the level of flow stress but the consideration of these parameters is not easy and needs a suitable database. Therefore, the following analysis can fairly demonstrate the averaged constitutive behavior of this material. It should also be noted that the initial grain size is believed to exert little effect on the hot flow stress (during hot working and in creep when intragranular dislocation creep is underway) but it has a strong influence on the recrystallization process and on the transition from single peak to cyclic behavior [38].

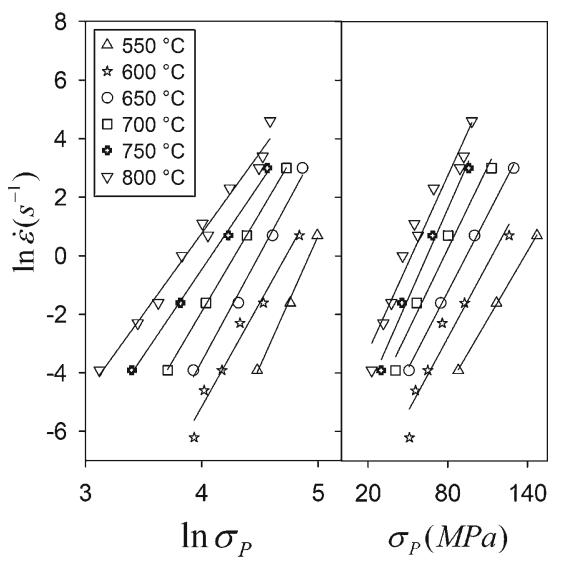

Fig. 1. Plots used to obtain the value of the stress multiplier $\alpha$.

\section{Results}

\subsection{The conventional apparent constitutive analysis}

Generally, the Zener-Hollomon parameter $Z=$ $\dot{\varepsilon} \exp (Q / R T)$ can be related to flow stress in different ways. The power law description of stress $\left(Z=A^{\prime} \sigma^{n^{\prime}}\right)$ is preferred for relatively low stresses (in analogy with the creep experiments) and the power law breakdown occurs at high stresses and the exponential law $\left(Z=A^{\prime \prime} \exp (\beta \sigma)\right)$ is found to be suitable in the latter case. However, as indicated before, the hyperbolic sine law $\left(Z=A\{\sinh (\alpha \sigma)\}^{n}\right)$ can be used for a wide range of temperatures and strain rates as it reduces to the power and exponential laws at low and high stresses, respectively. In the equations describing the power and exponential laws, $A^{\prime}, A^{\prime \prime}, n^{\prime}$, and $\beta$ are constants. The stress multiplier $\alpha$ is an adjustable constant which brings $\alpha \sigma$ into the correct range that gives linear and parallel lines in $\ln \dot{\varepsilon}$ versus $\ln \{\sinh (\alpha \sigma)\}$ plots, which can be estimated by $\alpha \approx \beta / n^{\prime}[25]$.

Based on the power and exponential laws, the slopes of the plots of $\ln \dot{\varepsilon}$ against $\ln \sigma_{\mathrm{P}}$ and $\ln \dot{\varepsilon}$ against $\sigma_{\mathrm{P}}$ can be used for obtaining the values of $n^{\prime}$ and $\beta$, respectively. This is shown in Fig. 1 and the subsequent linear regression of the data resulted in the average 


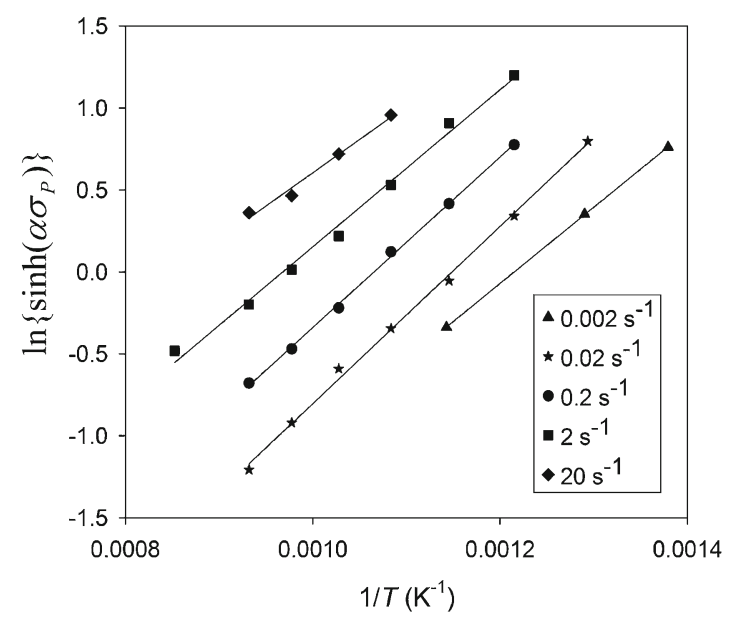

Fig. 2. Plot used to obtain the value of the apparent activation energy $Q$.

values of $\alpha \approx \beta / n^{\prime} \approx 0.013 \mathrm{MPa}^{-1}$. Moreover, taking natural logarithm from the hyperbolic sine equation together with partial differentiation and subsequent algebraic operations results in the following expression:

$$
\begin{gathered}
Q=R\left[\partial \ln \dot{\varepsilon} / \partial \ln \left\{\sinh \left(\alpha \sigma_{\mathrm{P}}\right)\right\}\right]_{T} . \\
\cdot\left[\partial \ln \left\{\sinh \left(\alpha \sigma_{\mathrm{P}}\right)\right\} / \partial(1 / T)\right]_{\dot{\varepsilon}}
\end{gathered}
$$

It follows that the slopes of the plots of $\ln \dot{\varepsilon}$ against $\ln \{\sinh (\alpha \sigma)\}$ and $\ln \{\sinh (\alpha \sigma)\}$ against $1 / T$ can be used for obtaining the value of $Q$. The latter type of plot is shown in Fig. 2. The linear regression of the data results in the average values of $Q \approx 205.5$ $\mathrm{kJ} \mathrm{mol}^{-1}$. Since no account was generally taken of the internal microstructural state and the obtained value of $Q$ was only derived from an Arrhenius plot with a linear range and the assumption that the microstructure remains constant, this should be called the apparent activation energy. However, this apparent $Q$ is close to the value of $197 \mathrm{~kJ} \mathrm{~mol}^{-1}$ for the lattice self-diffusion activation energy of copper [39].

Based on the hyperbolic sine law, the slope and the intercept of the plot of $\ln Z$ against $\ln \left\{\sinh \left(\alpha \sigma_{\mathrm{P}}\right)\right\}$ can be used for obtaining the values of $n$ and $\ln A$. The corresponding plot is shown in Fig. 3 using the apparent value of $Q$. The linear regression of the data results in the following equation:

$\dot{\varepsilon} \exp (205500 / R T)=5.80 \times 10^{10}\left\{\sinh \left(0.013 \times \sigma_{\mathrm{P}}\right)\right\}^{4.95}$.

Despite the visual examination of Fig. 3 and employing the correlation coefficient $\left(R^{2}\right)$, the ability of Eq. (2) in representation of the peak flow stresses of the OFHC copper can be better evaluated by calculating the root mean square error (RMSE) and the per-

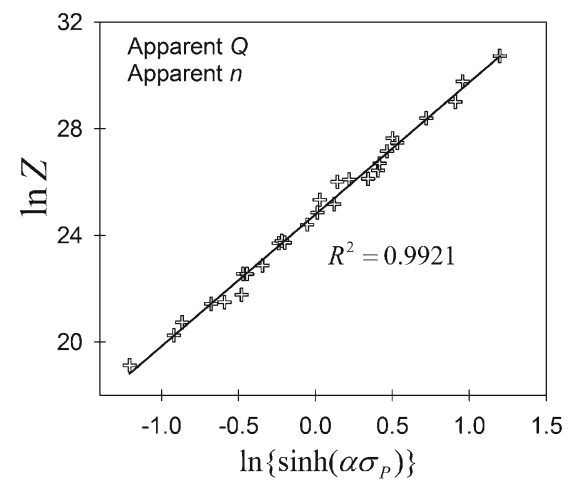

Fig. 3. Plot used to derive the representative constitutive equation based on the hyperbolic sine law.

centage of the average relative absolute error (AAE) using the following formulae:

$$
\begin{gathered}
\mathrm{RMSE}=\sqrt{\frac{1}{N} \sum_{i=1}^{N}\left(t_{i}-y_{i}\right)^{2},} \\
\mathrm{AAE}=\frac{1}{N} \sum_{i=1}^{N}\left|\frac{t_{i}-y_{i}}{t_{i}}\right| \times 100,
\end{gathered}
$$

where $t_{i}$ is the target output and $y_{i}$ is the model output. The values of the peak flow stress can be determined by using the following equation:

$$
\begin{aligned}
& \sigma=\frac{1}{\alpha}\left\{\sinh ^{-1}\left(\frac{Z}{A}\right)^{1 / n}\right\}= \\
& =\frac{1}{\alpha} \ln \left\{\left(\frac{Z}{A}\right)^{1 / n}+\left(\left(\frac{Z}{A}\right)^{2 / n}+1\right)^{1 / 2}\right\},
\end{aligned}
$$

or simply

$$
\sigma=\frac{1}{0.013} \times \sinh ^{-1}\left(\frac{\dot{\varepsilon} \exp (205500 / R T)}{5.80 \times 10^{10}}\right)^{1 / 4.95} .
$$

The average RMSE and AAE were determined as $2.82 \mathrm{MPa}$ and $3.19 \%$, respectively. These low error values show that Eq. (2) is suitable for prediction of peak flow stress.

Note that the value of $n=4.95$ is close to 5 . Recently it has been shown that when the deformation mechanism is controlled by the glide and climb of dislocations, a constant hyperbolic sine power of $n=$ 5 and self-diffusion activation energy $\left(Q_{\mathrm{sd}}\right)$ can be used to describe the appropriate stress [31]. Based on the apparent values of $n$ (near 5) and $Q$ (near 197 
Table 2. Data required for characterizing the temperature dependence of the lattice self-diffusion coefficient and the shear modulus [39]

\begin{tabular}{lccccc}
\hline Material & $D_{0}\left(\mathrm{~m}^{2} \mathrm{~s}^{-1}\right)$ & $Q_{\mathrm{SD}}\left(\mathrm{kJ} \mathrm{mol}^{-1}\right)$ & $\eta$ & $G_{0}(\mathrm{MPa})$ & $T_{\mathrm{M}}(\mathrm{K})$ \\
\hline AISI 304 and 316 stainless steel & $3.7 \times 10^{-5}$ & 280 & -0.85 & 81000 & 1680 \\
$\gamma$-Iron & $1.8 \times 10^{-5}$ & 270 & -0.91 & 81000 & $1184-1665 \lambda$ \\
Aluminum & $1.7 \times 10^{-4}$ & 142 & -0.50 & 25400 & 933 \\
Magnesium & $1.0 \times 10^{-4}$ & 135 & -0.49 & 16600 & 924 \\
Copper & $2.0 \times 10^{-5}$ & 197 & -0.54 & 42100 & 1356 \\
Nickel & $1.9 \times 10^{-4}$ & 284 & -0.64 & 78900 & 1726 \\
\hline
\end{tabular}

$\mathrm{kJ} \mathrm{mol}^{-1}$ ) as indicated by Eq. (2), it seems that this assumption works perfectly for OFHC copper. In the following sections, this issue will be revisited again.

\subsection{The physically based constitutive analysis}

By consideration of physically based material parameters $\left(n=5\right.$ and $\left.Q=Q_{\text {sd }}\right)$ and by taking into account the dependence of Young's modulus $(E)$ and self-diffusion coefficient $(D)$ on temperature in the hyperbolic sine law, the unified relation for describing the hot deformation behavior can be expressed as follows [31]:

$$
\dot{\varepsilon} / D=B\left[\sinh \left(\alpha^{\prime} \sigma / E\right)\right]^{5},
$$

where $D=D_{0} \exp \left(-Q_{\mathrm{sd}} / R T\right)$, in which $D_{0}$ is a preexponential constant. The constants $\alpha^{\prime}$ and $B$ are the modified stress multiplier and the hyperbolic sine constant, respectively. The consideration of hyperbolic sine power of 5 and self-diffusion activation energy gives a physical and metallurgical meaning to Eq. (7) and also reduces the number of unknown parameters and constant to $2\left(\alpha^{\prime}\right.$ and $\left.B\right)$. The former one results in a more reliable constitutive equation and the latter one simplifies the constitutive analysis and makes it possible to conduct comparative hot deformation studies.

In Eq. (7), the values of $D_{0}$ and $Q_{\text {sd }}$ can be taken from the Frost and Ashby tables [39]. In these tables, the dependence of the shear modulus $(G)$ on temperature in the form of $G / G_{0}=1+\eta(T-300) / T_{\mathrm{M}}$ is also available. Here, $G_{0}$ is the shear modulus at $300 \mathrm{~K}$, $T_{\mathrm{M}}$ is the melting temperature of the material, and $\eta=\left(T_{\mathrm{M}} / G_{0}\right) \mathrm{d} G / \mathrm{d} T$ shows the temperature dependence of the shear modulus. According to the relation $E=2 G(1+\nu)$, the value of $E$ can be estimated ( $\nu$ is usually taken as 0.3 ). Using the available data for copper (as shown in Table 2), the following expressions can be derived for $D$ and $E$ :

$$
\begin{gathered}
D=2.0 \times 10^{-5} \times \exp (-197000 / R T), \\
E=109460 \times\{1-0.54(T-300) / 1356\} .
\end{gathered}
$$

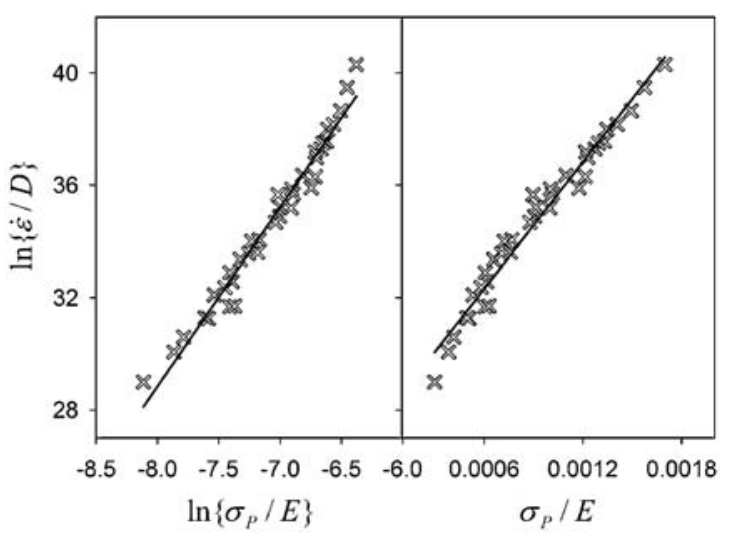

Fig. 4. Plots used to obtain the value of the modified stress multiplier $\alpha^{\prime}$.

It can be deduced that there are only two unknown parameters $\left(B\right.$ and $\left.\alpha^{\prime}\right)$. In order to find the value of $\alpha^{\prime}$, a similar approach to Section 3.1 was used, in which, the power and exponential laws were modified as $\dot{\varepsilon} / D=B^{\prime}\left(\sigma_{\mathrm{P}} / E\right)^{n^{\prime}}$ and $\dot{\varepsilon} / D=B^{\prime \prime} \exp \left(\beta^{\prime} \sigma_{\mathrm{P}} / E\right)$, respectively. It follows from these expressions that the slope of the plot of $\ln (\dot{\varepsilon} / D)$ against $\ln \left(\sigma_{\mathrm{P}} / E\right)$ and the slope of the plot of $\ln (\dot{\varepsilon} / D)$ against $\sigma_{\mathrm{P}} / E$ can be used for obtaining the values of $n^{\prime}$ and $\beta^{\prime}$, respectively. These plots are shown in Fig. 4. The linear regression of these data resulted in the average value of $\alpha^{\prime}$ $=\beta^{\prime} / n^{\prime}=1179$.

A visual comparison between Fig. 4 and Fig. 1 shows that in the physically based approach (Eq. (7)), unlike the apparent approach (the conventional hyperbolic sine law), there is no need to consider separate regression analysis for each deformation temperature in order to find the value of the stress multiplier $\alpha^{\prime}$. This shows that the consideration of the dependences of Young's modulus and self-diffusion coefficient on temperature and inserting these parameters into the constitutive equations significantly simplifies further regression analysis.

According to Eq. (7), the slope of the plot of $\{\dot{\varepsilon} / D\}^{0.2}$ against $\sinh \left\{\alpha^{\prime} \sigma_{\mathrm{P}} / E\right\}$ by fitting a straight line with the intercept of zero $(y=a x+0)$ was used for obtaining the value of $B^{0.2}=832.2$ (Fig. 5). The 


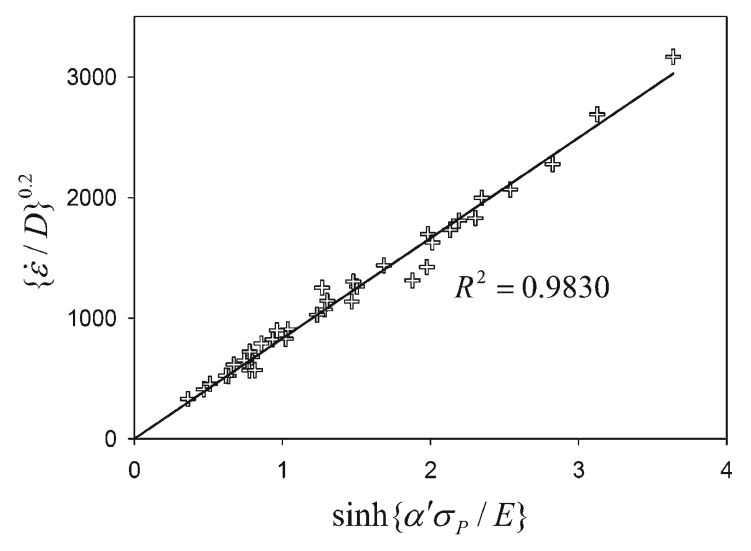

Fig. 5. Peak stresses presented according to Eq. (3).

resultant constitutive equation can be expressed as:

$$
\begin{aligned}
& \dot{\varepsilon} /\left\{2.0 \times 10^{-5} \times \exp (-197000 / R T)\right\}= \\
& =832.2^{5} \times\left\{\sinh \left(1179 \times \sigma_{\mathrm{P}} / E\right)\right\}^{5} .
\end{aligned}
$$

Therefore, a reliable constitutive equation for describing the hot working behavior of OFHC copper can be expressed as:

$$
\begin{gathered}
Z=\dot{\varepsilon} \exp (197000 / R T)= \\
=95.6^{5} \times\left\{\sinh \left(1179 \times \sigma_{\mathrm{P}} / E\right)\right\}^{5} .
\end{gathered}
$$

The values of the peak flow stress based on Eq. (11) can be determined by using the following equation:

$$
\sigma=\left\{\sinh ^{-1}(\dot{\varepsilon} / B D)^{0.2}\right\} \times E / \alpha^{\prime},
$$

or simply

$$
\begin{aligned}
& \sigma=\left(\frac{1356-0.54(T-300)}{14.6}\right) \times \\
& \times \sinh ^{-1}\left(\frac{\dot{\varepsilon} \times \exp (197000 / R T)}{95.6^{5}}\right)^{0.2} .
\end{aligned}
$$

The average RMSE and AAE were determined as $3.85 \mathrm{MPa}$ and $4.67 \%$, respectively. These low error values show that Eq. (11) is suitable for prediction of peak flow stress.

\section{Discussion}

As indicated before, the determination of apparent values of $n$ (near 5) and $Q$ (near $197 \mathrm{~kJ} \mathrm{~mol}^{-1}$ ) is in accordance with the deformation mechanism controlled by the glide and climb of dislocations. Therefore, it is possible to consider the value of $Q=197 \mathrm{~kJ} \mathrm{~mol}^{-1}$ with $n=5$ in the conventional hyperbolic sine law to find a new value for the hyperbolic sine constant

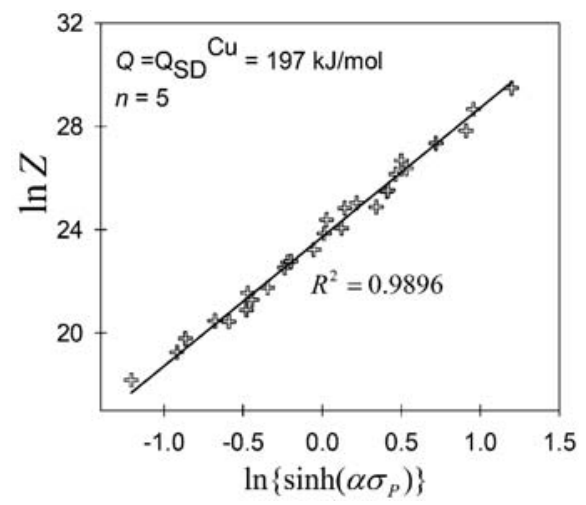

Fig. 6. Plot used to obtain the constant of the conventional hyperbolic sine equation by consideration of $Q=197 \mathrm{~kJ}$ $\mathrm{mol}^{-1}$ and $n=5$.

$(A)$, which in turn results in a reliable but simple constitutive equation. Again, based on the hyperbolic sine law, the intercept of the plot of $\ln Z$ (using $Q$ $\left.=197 \mathrm{~kJ} \mathrm{~mol}^{-1}\right)$ against $\ln \left\{\sinh \left(\alpha \sigma_{\mathrm{P}}\right)\right\}$ by setting the slope of $n=5$ can be used for obtaining the value of $\ln A$. The corresponding plot is shown in Fig. 6 . The good fit to experimental data justifies the consideration of $Q=197 \mathrm{~kJ} \mathrm{~mol}^{-1}$ and $n=5$ for OFHC copper. The linear regression of the data results in the following equation:

$$
Z=\dot{\varepsilon} \exp (197000 / R T)=114.9^{5}\left\{\sinh \left(0.013 \times \sigma_{\mathrm{P}}\right)\right\}^{5} .
$$

It can be seen that the values of the hyperbolic sine constants of Eqs. (11) and (14) are not the same, which can be ascribed to the small difference between $\alpha^{\prime} / E$ in Eq. (11) and the average value of $\alpha$ in Eq. (14). The value of $\alpha^{\prime} / E$ depends on the deformation temperature. Therefore, the value of $\alpha^{\prime} / E$ varies from 0.0129 to 0.0165 when the deformation temperature rises from 450 to $900^{\circ} \mathrm{C}$. It can be seen that the values of $\alpha^{\prime} / E$ are relatively comparable with the average value of $\alpha \approx 0.013 \mathrm{MPa}^{-1}$. This is an interesting finding because it means that the hyperbolic sine terms of Eqs. (11) and (14) are in fact the same. This shows that the two approaches used in the present work are consistent with each other. Therefore, it can be concluded that the theoretical values of $n=5$ and the self-diffusion activation energy can be used in the conventional hyperbolic sine equation to construct the appropriate constitutive equation. However, as discussed before, the consideration of Eq. (7) has a unique advantage of simplifying the constitutive analysis.

\section{Conclusions}

In the current work, the constitutive behavior of OFHC copper during compressive hot deforma- 
tion was studied through constitutive analyses based on the proposed physically based and apparent approaches. The following conclusions can be drawn from this study:

1. Both the apparent approach and the proposed physically based approach which accounts for the dependence of the Young's modulus and the self-diffusion coefficient of copper on temperature are able to characterize the hot working behavior of OFHC copper. However, the proposed physically based approach not only results in a more reliable constitutive equation, but also significantly simplifies the constitutive analysis.

2 . The theoretical exponent of 5 and the lattice self-diffusion activation energy of copper $\left(197 \mathrm{~kJ} \mathrm{~mol}^{-1}\right)$ can be set in the hyperbolic sine law to describe the peak flow stresses and the resulting constitutive equation is consistent with that resulted from the proposed physically based approach.

3 . The values of $\alpha^{\prime} / E$ were found to be relatively comparable with the average value of the original stress multiplier $(\alpha)$, which means that the hyperbolic sine terms of $\dot{\varepsilon} \exp (Q / R T)=A\{\sinh (\alpha \sigma)\}^{n}$ and $\dot{\varepsilon} / D=B\left[\sinh \left(\alpha^{\prime} \sigma / E\right)\right]^{5}$ are essentially the same.

\section{References}

[1] Brady, G. S., Clauser, H. R.: Materials Handbook, $12^{\text {th }}$ edition. New York, McGraw-Hill 1986.

[2] Prasad, Y. V. R. K., Rao, K. P.: Journal of Engineering Materials and Technology, 128, 2006, p. 158. doi:10.1115/1.2172275

[3] Zhang, H., Zhang, H.-G., Peng, D.-S.: Transactions of Nonferrous Metals Society of China, 16, 2006, p. 562. doi:10.1016/S1003-6326(06)60098-8

[4] Blaz, L., Sakai, T., Jonas, J. J.: Metal Science, 17, 1983, p. 609. doi:10.1179/030634583790420448

[5] Mirzadeh, H., Najafizadeh, A.: ISIJ International, 53, 2013, p. 680. doi:10.2355/isijinternational.53.680

[6] Kratochvíl, P., Schindler, I., Hanus, P.: Kovove Mater., 44, 2006, p. 321.

[7] Dobrzanski, L. A., Borek, W.: Archives of Civil and Mechanical Engineering, 12, 2012, p. 299. doi:10.1016/j.acme.2012.06.016

[8] Opiela, M., Grajcar, A.: Archives of Civil and Mechanical Engineering, 12, 2012, p. 327. doi:10.1016/j.acme.2012.06.003

[9] Kuc, D., Niewielski, G., Hadasik, E., Radwanski, K.: Archives of Civil and Mechanical Engineering, 4, 2004, p. 85.

[10] Yan, W., Fu, G.: Materiali in Tehnologije, 46, 2012, p. 637.

[11] Mirzadeh, H., Najafizadeh, A.: Materials and Design, 31, 2010, p. 1174. doi:10.1016/j.matdes.2009.09.038

[12] Mirzadeh, H., Parsa, M. H.: Journal of Alloys and Compounds, 614, 2014, p. 56. doi:10.1016/j.jallcom.2014.06.063

[13] Tamirisakandala, S., Vedam, B. V., Bhat, R. B.: Journal of Materials Engineering and Performance, 12, 2003, p. 661. doi:10.1361/105994903322692466
[14] Tehovnik, F., Žužek, B., Arh, B., Burja, J., Podgornik, B.: Materiali in Tehnologije, 48, 2014, p. 137.

[15] Nemat-Nasser, S., Ni, L., Okinaka, T.: Mechanics of Materials, 30, 1998, p. 325. doi:10.1016/S0167-6636(98)00055-6

[16] Mirzadeh, H., Cabrera, J. M., Najafizadeh, A.: Metallurgical and Materials Transactions A, 43, 2012, p. 108.

[17] Lin, Y. C., Chen, X. M.: Materials and Design, 32, 2011, p. 1733. doi:10.1016/j.matdes.2010.11.048

[18] Zhang, H., Dong, X., Du, D., Wang, Q.: Materials Science and Engineering A, 564, 2013, p. 431. doi:10.1016/j.msea.2012.12.001

[19] Liu, R., Salahshoor, M., Melkote, S. N., Marusich, T.: Procedia CIRP, 13, 2014, p. 249. doi:10.1016/j.procir.2014.04.043

[20] Lin, Y. C., Chen, M. S., Zhong, J.: Computational Materials Science, 42, 2008, p. 470. doi:10.1016/j.commatsci.2007.08.011

[21] Mirzadeh, H., Najafizadeh, A.: Materials Science and Engineering A, 527, 2010, p. 1856. doi:10.1016/j.msea.2009.11.013

[22] Lin, Y. C., Chen, X. M., Wen, D. X., Chen, M. S.: Computational Materials Science, 83, 2014, p. 282. doi:10.1016/i.commatsci.2013.11.003

[23] Wang, L., Liu, F., Zuo, Q., Chen, C. F.: Materials and Design, 47, 2013, p. 737. doi:10.1016/j.matdes.2012.12.074

[24] Lin, Y. C., Wen, D. X., Deng, J., Liu, G., Chen, J.: Materials and Design, 59, 2014, p. 115. doi:10.1016/j.matdes.2014.02.041

[25] Mirzadeh, H., Cabrera, J. M., Prado, J. M., Najafizadeh, A.: Materials Science and Engineering A, 528, 2011, p. 3876. doi:10.1016/i.msea.2011.01.098

[26] Pernis, R., Kasala, J., Bořuta, J.: Kovove Mater., 48, 2010, p. 41.

[27] Kugler, G., Knap, M., Palkowski, H., Turk, R.: Metallurgija, 43, 2004, p. 267.

[28] Schindler, I., Kawulok, R., Kulveitová, H., Kratochvíl, P., Š́ma, V., Knapiński, M.: Acta Physica Polonica A, 122, 2012, p. 610 .

[29] Mirzadeh, H., Najafizadeh, A., Moazeny, M.: Metallurgical and Materials Transactions A, 40, 2009, p. 2950.

[30] Bradaskja, B., Pirnar, B., Fazarinc, M., Fajfar, P.: Steel Research Int., 82, 2011, p. 346. doi:10.1002/srin.201000036

[31] Mirzadeh, H., Cabrera, J. M., Najafizadeh, A.: Acta Materialia, 59, 2011, p. 6441. doi:10.1016/j.actamat.2011.07.008

[32] Sample, V. M., Fitzsimons, G. L., DeArdo, A. J.: Acta Metallurgica, 35, 1987, p. 367. doi:10.1016/0001-6160(87)90244-6

[33] Prasad, Y. V. R. K., Rao, K. P.: Philosophical Magazine, 84, 2004, p. 3039. doi:10.1080/14786430410001716205

[34] Kim, Y., Lee, S. H., Lee, S., Noh, J. W.: Materials Science and Engineering A, 552, 2012, p. 276. doi:10.1016/j.msea.2012.05.040

[35] Tanner, A. B., McDowell, D. L.: International Journal of Plasticity, 15, 1999, p. 375. doi:10.1016/S0749-6419(98)00061-8

[36] Mirzadeh, H., Najafizadeh, A., Moazeny, M.: Ma- 
terials Science and Technology, 26, 2010, p. 501. doi:10.1179/026708309X12468927349532

[37] Mirzadeh, H., Najafizadeh, A.: Materials Science and Engineering A, 527, 2010, p. 1160. doi:10.1016/j.msea.2009.09.060

[38] Mirzadeh, H., Parsa, M. H., Ohadi, D.: Materials Science and Engineering A, 569, 2013, p. 54. doi:10.1016/j.msea.2013.01.050
[39] Frost, H. J., Ashby, M. F.: Deformation-Mechanism Maps: The Plasticity and Creep of Metals and Ceramics. Oxford, Pergamon Press 1982. 